\section{Utility of in Vitro Propagation for Field-grown Broccoli: Effect of Genotype and Growing Season}

\author{
M.W. Farnham ${ }^{1}$ and B.V. Nelson ${ }^{2}$ \\ U.S. Vegetable Laboratory, Agricultural Research Service, U.S. Department \\ of Agriculture, 2875 Savannah Highway, Charleston, SC 29414
}

Additional index words. Brassica oleracea Botrytis group, shoot regeneration

\begin{abstract}
We examined an in vitro culture method for propagating unconditioned, fieldgrown broccoli (Brassica oleracea L. Botrytis group) from peduncle explants by testing 20 cultivars in fall and spring. Propagation was affected significantly by genotype (cultivar) and season. The percentage of explants regenerating shoots was significantly higher for cultivars grown in spring $(17 \%$ to $100 \%)$ than in fall $(0 \%$ to $66 \%)$. Shoot regeneration from explants of plants within a cultivar also varied significantly (0\% to $100 \%)$. Additionally, the number of propagules produced per explant was influenced by cultivar and was highly correlated with the percentage of explants regenerating shoots. This method for propagating field-grown broccoli lines is useful, but its applicability can be limited by genetic and environmental factors.
\end{abstract}

Shoot regeneration and in vitro propagation of Brassica oleracea vegetables have been reported using a variety of explants, including leaves (Dunwell, 1981; Johnson and Mitchell, 1978), axillary buds (Clare and Collin, 1973), stems (Dietert et al., 1982), peduncles (Christey and Earle, 1991), curds (Walkey and Woolfitt, 1970), and flower buds (Anderson and Carstens, 1977; Anderson et al., 1977). Most of these methods are characterized by a low percentage of explants regenerating into shoots. However, Anderson and Carstens (1977), using broccoli flower buds, and Christey and Earle (1991), using peduncles from various $B$. oleracea crops, reported relatively high ( $>75 \%$ ) shoot regeneration levels. Stringam (1977) also reported similar high levels for B. napus L. peduncle explants. Shoot regeneration rates reported by the above authors and short periods ( $\approx 10$ weeks) required to obtain potted plants make the described methods practical for applications such as maintaining haploid and male-sterile lines and multiplying novel genotypes rapidly. The number of clones that can be produced using these methods is nearly limitless. The brief interval from explant to shoot and the minimal callusing of explants also reduces the potential for somaclonal variation to alter genotypes. In addition, these in vitro methods can be used with gene transfer methods (Fry et al., 1987)

\footnotetext{
Received for publication 22 Sept. 1992. Accepted for publication $10 \mathrm{Feb}$. 1993. Mention of a trademark, proprietary product, or vendor does not constitute a guarantee or warranty of the product by the U.S. Dept. of Agriculture and does not imply its approval to the exclusion of other products or vendors that might also be suitable. The cost of publishing this paper was defrayed in part by the payment of page charges. Under postal regulations, this paper therefore must be hereby marked advertisement solely to indicate this fact.

${ }^{1}$ Research Geneticist.

${ }^{2}$ Biological Laboratory Technician.
}

and in shoot induction and morphogenesis studies (Julliard et al., 1992).

Few previous studies of $B$. oleracea crops using in vitro propagation methods have considered cultivar effects on shoot regeneration and propagation within crop groups. Most methods have been tested on one or two cultivars. Several authors have examined and observed regeneration variability among Brassica species (Dietert et al., 1982; Dunwell, 1981), and Christey and Earle (1991) evaluated differences among B. oleracea crops [e.g., broccoli vs. cabbage (B. oleracea L. Capitata group)]. However, none of these studies reports on variation for a more extensive genotype sampling within a crop group using a method that gives high shoot regeneration rates. Additionally, plants typically studied for in vitro regeneration are environmentally conditioned or grown under controlled conditions in a growth chamber or greenhouse. The need to condition plants makes propagation a more difficult task in a field breeding program. A method that can be used directly on plants grown in and selected from field nurseries has greater potential.

The objectives of this study were to 1) evaluate cultivar and intracultivar effects on the ability to propagate broccoli from peduncle explants; 2) determine if unconditioned, field-grown broccoli would propagate efficiently; and 3) discern if the growth season (spring or fall) influenced propagability.

Twenty broccoli cultivars were grown in field trials at Charleston, S. C., during Fall 1991 and Spring 1992. The two trials were conducted in adjacent fields with identical soil types. All cultural practices (e.g., cultivation, fertilization, and irrigation) were standard for local conditions (Cook and Ezell, 1983). The design was a randomized complete block with three replications. Each plot was a single row of 15 plants. Spacing between rows and between plants within a row was 102 and $30 \mathrm{~cm}$, respectively. Broccoli heads were harvested from five plants per plot when heads reached $10 \mathrm{~cm}$ in diameter. Peduncles from these heads were used as explant sources for propagation. Explants were dissected from the fourth, fifth, ninth, and tenth peduncles, counting from the oldest to youngest (from the base of the head to the top) on each head from all plants. Fifteen plants of each cultivar were sampled during each growing season.

Peduncle explants were surface-sterilized and cultured by methods and conditions described by Christey and Earle (1991). Peduncle sections $5.0 \mathrm{~mm}$ long were placed in $100 \times 20$-mm petri dishes on Linsmaier-Skoog (LS) medium (Linsmaier and Skoog, 1965) containing $3 \%$ sucrose and $1.0 \mathrm{mg} 6-$ benzlyaminopurine/liter. Medium $\mathrm{pH}$ was adjusted to 5.7 with $1.0 \mathrm{~m} \mathrm{KOH}$ before autoclaving. Ten explants (two or three from each of the four peduncles tested) per plant were sampled to evaluate shoot regeneration. Petri dishes were sealed with parafilm (American Can Co., Greenwich, Corm.). Cultures were incubated at $25 \mathrm{C}$ under a daily 16 -h light intensity of 80 to $100 \mu \mathrm{mol} \cdot \mathrm{m}^{-2} \cdot \mathrm{s}^{-1}$ supplied by cool-white fluorescent bulbs. The number of explants regenerating shoots was determined weekly for 5 weeks. We observed no increase in the percentage of explants regenerating shoots after 4 weeks in culture. After 5 weeks, the number of shoots per explant was counted, and a subsample of five to 10 shoots per original, cultured plant was transferred to hormone-free LS medium for rooting and then transferred to soil.

Peduncle explant location within a head had no effect on explant regeneration from a particular plant. Because explants from different locations exhibited similar regeneration rates, location was ignored and all explants from a single head were treated as an individual plant sample to evaluate genotype and growing season effects.

The ability to propagate field-grown broccoli clonally using in vitro culture of peduncle explants was influenced largely by cultivar (Table 1). Significant cultivar differences for the percentage of explants regenerating shoots were observed in both seasons. There was no statistical evidence of genotype $\mathrm{x}$ season interaction for mean generation. Cultivar means were $0 \%$ to $66 \%$ in the fall and $17 \%$ to $100 \%$ in the spring (Table 2). These ranges are much greater than reported previously for a smaller sample of broccoli cultivars (Christey and Earle, 1991).

Plants within a cultivar differed in their ability to induce explant shoot regeneration.

Table 1. Analysis of variance for season and cultivar effects on mean percent explant regeneration of tested cultivars.

\begin{tabular}{lrc}
\hline \hline Source & df & $\mathrm{mS}$ \\
\hline Season & 1 & 20830 \\
Replications (season) & 4 & 472 \\
Cultivar & 19 & $2045^{* *}$ \\
Season $\times$ cultivar & 19 & 559 \\
Error & 76 & 377 \\
\hline
\end{tabular}

**Significant at $P \leq 0.01$. 
Table 2. Mean percentage of explants regenerating shoots for each cultivar and the range of explant regeneration (percentage) within a cultivar tested in fall and spring.

\begin{tabular}{lcccc}
\hline \hline & \multicolumn{3}{c}{ Explants regenerating shoots (\%) } \\
\cline { 2 - 5 } Cultivar & \multicolumn{2}{c}{ Fall 1991 } & \multicolumn{2}{c}{ Spring 1992 } \\
\cline { 2 - 5 } Mean & Range & Mean & Range \\
\hline DeCicco & 45 & $0-100$ & 67 & $0-100$ \\
Walabrese & 39 & $0-100$ & 35 & $20-100$ \\
Green Duke & 30 & $0-60$ & 7 & 9 \\
Packman & 6 & $0-20$ & 63 & $20-100$ \\
Gem & 31 & $0-80$ & 82 & $400-100$ \\
Baccus & 45 & $0-100$ & 100 & $100-100$ \\
Sy m ph on y & 9 & $0-50$ & 45 & $0-80$ \\
Pirate & 66 & $0-100$ & 95 & $70-100$ \\
Embassy & 3 & $0-20$ & 17 & $0-70$ \\
XPH5611 & 40 & $0-70$ & 66 & $0-100$ \\
Florette & 59 & $0-100$ & 58 & $0-100$ \\
Early Dawn & 64 & $0-100$ & 87 & $60-100$ \\
Southern Comet & 35 & $0-90$ & 41 & $0-100$ \\
Citation & 63 & $10-100$ & 69 & $0-100$ \\
Green Goliath & 4 & $0-100$ & 51 & $20-90$ \\
Green Comet & 46 & $0-100$ & 64 & $10-100$ \\
Premium Crop & 31 & $0-100$ & 59 & $0-100$ \\
Emperor & 38 & $0-90$ & 37 & $0-100$ \\
Green Valiant & 0 & $0-0$ & 36 & $0-70$ \\
Mean & 36 & $0-90$ & 56 & $0-90$ \\
\hline
\end{tabular}

${ }^{2}$ DeCicco, Calabrese, and Waltham 29 are open-pollinated cultivars; all others are $\mathrm{F}_{1}$ hybrids.

'Observed range within a cultivar for the percentage of explants from each plant that regenerated shoots; 15 plants were sampled per cultivar.

This variability was common and ranged as high as $0 \%$ to $100 \%$ (Table 2). Within-cultivar variation was similar for open-pollinated cultivars, such as Waltham 29 and Calabrese, and for modem $\mathrm{F}_{1}$ hybrids. Previous researchers have not discussed within-cultivar differences. In many studies, authors do not indicate how many plants per cultivar are sampled. Our results indicate that this could be a primary consideration when propagating a line.

The season in which broccoli was grown influenced the effectiveness of in vitro propagation. Explant shoot regeneration in spring was significantly different (Table 1) and about twice as efficient as regeneration in fall (Table 2). Cultivars that showed little or no regeneration in fall ('Green Duke' and 'Emperor') exhibited significantly greater regeneration in spring. Additionally, only $10 \%$ of all individual plants sampled in spring gave no regenerating explants compared to $29 \%$ in fall. Apparently, the fall environment negatively conditioned plants so that explants were less likely to regenerate shoots.

In fall and spring, the percentage of explants regenerating shoots was highly correlated with the number of shoots that was produced per regenerating explant (Fig. 1, spring only). Cultivars or plants that exhibited high regeneration rates produced more shoots per explant than those with low rates. Thus, the potential number of clones that can be produced by a plant or line is determined by the percentage of explants regenerating shoots and explant shoot count.

Means for the percentage of explants regenerating shoots using field-grown cultivars were less than means reported by Christey and Earle (1991) using greenhouse-grown plants and by Anderson and Carstens (1977) using temperature-conditioned plants. We sampled peduncles from broccoli heads before bolting; in contrast, Christey and Earle sampled peduncles from bolting heads. However, we do not consider this difference to be critical because, in a preliminary test, we sampled peduncles of plants at the two stages and observed similar regeneration rates (data not shown).

Ten cultivars in the fall field trial were brought through the entire culturing process from original plants to propagules in a spring nursery. About 20 propagated plants per cultivar were acclimated and transplanted to the field. For each cultivar examined, the propagated transplants and an equal number of transplants produced from seed were grown in adjacent rows, and plant appearance was compared. Similar to Christey and Earle (1991) and Anderson and Carstens (1977), we observed a high rate of successful transfers to soil $(>80 \%)$ when plants were conditioned properly after being removed from culture vessels. We also observed no apparent morphological differences among cultivars that were moved through the culturing process and cultivars produced from seed.

The failure of many field-grown broccoli genotypes to respond to in vitro propagation could make it difficult to use this method routinely when unique individuals or specific genotypes are identified or grown in field nurseries. When environmental conditions in the field are conducive to in vitro propagation, there is a high probability (in this experiment, $P=0.9$ during spring) that peduncle explant cultures can be used to propagate individual plants or line. However, the ability to regenerate will not always guarantee a large number of propagules.

Our results show that the method described can be used to culture unconditioned plants

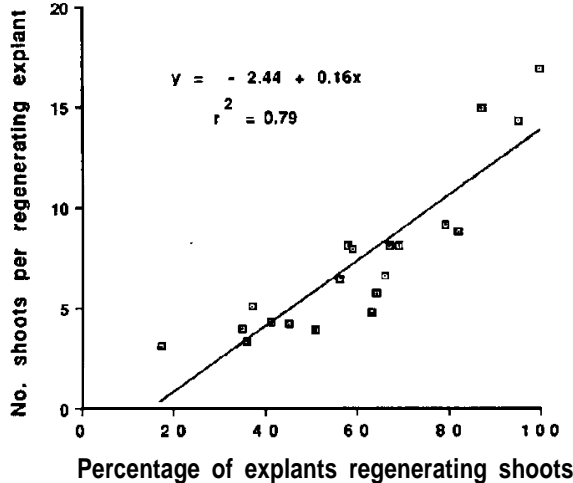

Fig. 1. Relationship between mean explant shoot regeneration (percentage) and the average number of shoots per regenerating explant for 20 broccoli cultivars grown in spring, The line represents the best linear fit for the data; $\mathrm{y}=$ $(-2.44)+0.16 \mathrm{x}$ and $r^{2}=0.79$

from the field, but that its effectiveness can be influenced by the genotype being cloned and the season in which the plant has been growing. Additionally, the results indicate the importance of testing a wide array of genotypes within a $B$ oleracea crop group before assuming an in vitro method can be applied to the entire crop.

\section{Literature Cited}

Anderson, W.C. and J.B. Carstens. 1977. Tissue culture propagation of broccoli, Brassica oleracea (Italica group), for use in $\mathrm{F}_{1}$ hybrid seed production. J. Amer. Soc. Hort. Sci. 102:69-73.

Anderson, W.C., G.W. Meagher, and A.G. Nelson. 1977. Cost of propagating broccoli plants through tissue culture. HortScience 12:543-544.

Christey, M.C. and E.D. Earle. 1991. Regeneration of Brassica oleracea from peduncle explants. HortScience 26:1069-1072

Clare, M.V. and H.A. Collin. 1973. Meristem culture of brussels sprouts. Host. Res. 13:111-118.

Cook, W.P. and D.O. Ezell. 1983. Commercial broccoli production in South Carolina. Clemson Univ. Coop. Ext. Serv. Hort. Lflt. 52.

Dietert, M. F., S.A. Barron, and O.C. Yoder. 1982 Effects of genotype on the in vitro culture in the genus brassica. Plant Sci. Lett. 26:233-340.

Dunwell, J.M. 1981. In vitro regeneration from excised leaf discs of three Brassica species. J. Expt. Bet. 32:789-799.

Fry, J., A. Barnason, and R.B. Horsch. 1987. Transformation of Brassica napus with Agrobacterium tumefaciens based vectors. Plant Cell Rpt. 6:321325.

Johnson, B.B. and E.D. Mitchell, Jr. 1978. In vitro propagation of broccoli from stem, leaf, and leaf rib explants. HortScience 13:246-247.

Julliard, J., L. Sossountzov, Y. Habricot, and G. Pelletier. 1992. Hormonal requirement and tissue competency for shoot organogenesis of 2 cultivars of Brassica napus. Physiol. Plant. 84(4):521-530.

Linsmaier, E.M. and F. Skoog. 1965. Organic growth factor requirements of tobacco tissue culture. Physiol. Plant. 18:100-127.

Stringam, G.R. 1977. Regeneration in stem explants of haploid rapeseed (Brassica napus L.) Plant Sci. Lett. 9:115-119.

Walkey, D.G. and J. M. G. Woolfitt. 1970. Rapid clonal multiplication of cauliflower by shake culture. J. Hort. Sci. 45205-206. 